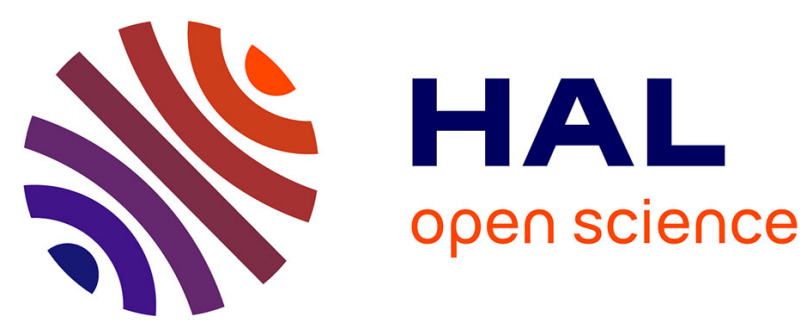

\title{
We predict a riot: inequity, relative deprivation and collective destruction in the laboratory
}

Guillaume Dezecache, James M Allen, Jorina von Zimmermann, Daniel C Richardson

\section{- To cite this version:}

Guillaume Dezecache, James M Allen, Jorina von Zimmermann, Daniel C Richardson. We predict a riot: inequity, relative deprivation and collective destruction in the laboratory. Proceedings of the Royal Society B: Biological Sciences, 2021, 288 (1959), pp.20203091. 10.1098/rspb.2020.3091 . hal-03402228

\section{HAL Id: hal-03402228 \\ https://hal.science/hal-03402228}

Submitted on 25 Oct 2021

HAL is a multi-disciplinary open access archive for the deposit and dissemination of scientific research documents, whether they are published or not. The documents may come from teaching and research institutions in France or abroad, or from public or private research centers.
L'archive ouverte pluridisciplinaire HAL, est destinée au dépôt et à la diffusion de documents scientifiques de niveau recherche, publiés ou non, émanant des établissements d'enseignement et de recherche français ou étrangers, des laboratoires publics ou privés. 


\section{We predict a riot: inequity, relative deprivation} and collective destruction in the lab

Guillaume Dezecache $e^{a, b, \&}$, James M. Allen ${ }^{a, \&}$,

${ }^{a}$ Department of Experimental Psychology, University College London, London, United Kingdom; ${ }^{b}$ Université Clermont Auvergne, CNRS, LAPSCO, Clermont-Ferrand, France.

$9 \quad$ *Corresponding Author: Daniel C. Richardson dcr@eyethink.org

10 \&Eual contribution 


\section{ABSTRACT}

13 Riots are unpredictable and dangerous. Our understanding of the factors that cause riots are 14 based on correlational observations of population data, or post hoc introspection of individuals.

15 To complement these accounts, we developed innovative experimental techniques, investigated 16 the psychological factors of rioting, and explored their consequences with agent-based 17 simulations. We created a game, 'Parklife', that physically co-present participants played using 18 smartphones. In two teams, participants tapped on their screen to grow trees and flowerbeds on 19 separate but adjacent virtual parks. Participants could also tap to vandalise the other team's park. 20 In some conditions, we surreptitiously introduced inequity between the teams so that one (the 21 disadvantaged team) had to tap more for each reward. The experience of inequity caused the 22 disadvantaged team to engage in more destruction, and to report higher relative deprivation and 23 frustration. Agent-based models suggested that acts of destruction were driven by the interaction 24 between individual level of frustration and the team's behaviour. Our results provide insights into 25 the psychological mechanisms underlying collective action.

27 Keywords: riots, relative deprivation, social identification, collective action, Parklife 


\section{INTRODUCTION}

Riots - defined as a 'violent demonstration or clash of more than 100 citizens involving the use of physical force' [1] - have long been a central topic in the social sciences and public debates due to their societal consequences. In the London riots of 2011, five people died, many more were injured, and property damage worth more than $£ 200$ million [2].

Why do people engage in riots? Politicians may caricature rioters as criminal-minded individuals [3], but scientific investigation has shown the reasons to be varied. Perhaps the leading psychological explanation for riots has been Relative Deprivation Theory (RDT) [4]. RDT stated that when people perceive a difference between what they have and what they believe they deserve, they feel relatively deprived. As the perceived disparity grows, so do frustration and resentment, increasing the likelihood for engagement in collective violence. This theory has contributed to explaining puzzling cases of collective violence, such as the bread riots of the $18^{\text {th }}$ century, in which people may not have suffered from starvation, but engaged in collective violence, possibly because what drove them to act was the relative (i.e., as compared to other groups in the society) and not absolute level of deprivation [4].

Though popular, RDT has been subjected to much criticism [5,6]. Sociological work has failed to reveal a clear association between deprivation indices (such as economic deprivation) and riots $[6,7]$. For example, economically-deprived neighbourhoods were not more riotous than others during the 1960s racial disorders in the US [8]. Economic deprivation is not the same as relative deprivation (the latter is subjective and not necessarily linked to economic hardship), but the idea that relative deprivation cannot explain the emergence of riots has since been a major assumption in the field.

These criticisms, however, are themselves limited by a conceptual flaw and the practical problem of directly measuring relative deprivation and riot participation. Past tests used imperfect proxies for relative deprivation, such as aggregate (rather than individual) and objective (rather than subjective) measures of deprivation [10]. Imperfect proxies for rioting were also used, such as occurrences of disorders in a given neighbourhood, a measure which cannot be linked to specific individuals whose level of relative deprivation is known. People's reported willingness to participate in a riot was measured, rather than actual participation (e.g., [11,12]). Even though there is evidence that relative deprivation (and particularly, group or fraternal relative deprivation

61 or the extent to which one feels she belongs to a deprived group [13]) can be associated with 
62 willingness to join protests [14] or endorse violent actions [15], it has not been shown that it causes

63 people to engage in collective destruction.

In recent literature, RDT and its relationship with hostile aggression has sparked new empirical study [13]. For example, Greitemeyer \& Sagioglou [16,17] found that participants told that they were of lower socio-economic status (SES) behaved more aggressively than participants told they were of higher SES. At the group level, only one study has - to our knowledge - directly investigated the relationship between the experience of inequity and collective hostile aggression. Abbink, Masclet \& Mirza [18] showed that small groups of participants treated with inequity coordinated to deprive the favoured groups of their earnings. In this case however, the outcome of the violent behaviour is instrumental (i.e., to reduce others' earnings) and may not correspond to core motivations for hostile aggression. Additionally, feelings of relative deprivation were not measured. This is needed to draw conclusions about any relationship between relative deprivation and destructive collective action. As such, a direct test of the association between the subjective feeling of relative deprivation and actual participation in collective violence is, to our knowledge, missing.

Besides relative deprivation and associated feelings of frustration, social identification (i.e., how much we feel we are part of the same group as others) plays a major role in the emergence of riots. Riots emerge through changes in social identification, beliefs that there is a shared problem and that collective action can prove efficient to change things $[3,19,20]$.

In this work, we sought to experimentally examine the causal role of relative deprivation in the emergence of riot-like phenomena, as well as to measure the importance of social identification in the making of collective action. We developed a lab-based experiment to identify causal factors, and modelled their interactions in agent-based simulations.

The experiment used a group interactive computer game, Parklife, that large numbers of physically co-present participants can play simultaneously using smartphones or tablets. In 91 contrast to many games used in psychology, Parklife can be played in the physical presence of 92 other participants. Parklife resembles popular 'time management' apps in which players expend 93 effort to develop resources, and are rewarded by a growing world. Participants are randomly 94 placed into two teams. By varying the comparative effort to create "park features", we induce 95 feelings of relative deprivation in the disadvantaged team. We therefore have two conditions: the 
equal game with no difference between the teams, and the unequal game where the disadvantaged team must work harder for equal rewards. By allowing (and measuring) vandalism of the other park across teams (advantaged and disadvantaged) and conditions (equal and unequal), we tested the effect of relative deprivation on vandalism.

More specifically, in the experiment, participants are invited to the lab and to sit around a table.

They are randomly assigned to two teams, and two empty parks are displayed on a large shared screen, visible to all (Figure 1). By tapping on a circle on their device, participants contribute towards their team's total work, which is displayed by a rising bar at the side of the park. Once a second, the average number of team members working is calculated (thereby reducing the impact of different team sizes), and added to the team's bar (visible to the side of each team's park). It takes 4 units of work per team for the bar to reach the top, at which point a park feature (e.g., a bench or flower bed) is built. If all members of a team are working, it thus takes 4 seconds to build a feature. Participants also have the option of switching their efforts from 'do' to 'undo'. Tapping 'undo' contributes towards a second bar on the screen. When the undo bar has filled, a feature in the park of the other team is vandalised, appearing on screen to be broken, and as before it takes 4 units of vandalism to destroy the park of the other team. A third option is available to players, that is 'to do nothing'. As the aim of the game is to build as many park features as possible, regardless of the state of the other park (as announced by the instructions), switching to 'undo' or to not tap at all seem irrational. As the state of the other team's park has no direct bearing on a team's success, participants are taking away effort from improving their own team's park when tapping 'undo' or doing nothing. Aggressive acts are operationalized as the individual and collective decisions to tap 'undo' rather than 'do' or just staying idle.

In each session, participants played two games of Parklife, each 3 minutes long. In one of the games, the two teams had to do equal amounts of work to be rewarded with a park feature (the

122 equal game). In the other game, the unequal game, one of the teams had to tap twice as much 123 to be rewarded with each feature (i.e., the disadvantaged team must now produce 8 units of work 124 to build a feature), thereby producing an inequity of reward between the teams. This inequity was 125 not announced to participants. We reasoned that this structural difference in the game (which 126 participants experienced as they play) would induce feelings of relative deprivation in the 127 disadvantaged team and cause its members to engage in more acts of vandalism against the 128 opposing team as compared to the other (advantaged) team. Note also that the costs of vandalism 129 remain equal in both teams, irrespective of the type of games (unequal or equal). Although less 
costly than building, the vandalism option remained more costly than staying idle, a low-cost and non-aggressive option, explicitly available to all players.

For players on the disadvantaged team, their efforts to build a park returns fewer rewards. Switching to vandalism might be a way to affect a change in the game with lower effort. But crucially there are different outcomes too. Players' switching to vandalising make the choice to abandon the alternative (the more effortful action of building the park), and instead decide to engage in lower effort, anti-social action against the other team (even though that indirectly harms their own park too). The effort difference is a feature of our paradigm that may parallel realworld situations. The conditions under which participants make that sort of choice (abandoning one type of effortful action to invest in antisocial actions ) are precisely what we want to investigate here.

After each game, we privately polled participants about their emotional state, their feelings towards each other, the opposing team, and the game that they played. We counterbalanced several game features between groups such as the order of the equal and unequal games and whether the disadvantaged team was red or blue.

Our experimental paradigm captures a key aspect of riots: they are a complex emergent phenomenon. We then employed agent based models to provide insight into complex behaviour that unfolds over time [21]. These models tested a number of hypotheses related to the central mechanisms that drive emergent phenomena in collective behaviour - frustration and relative deprivation, social identification and social norms - and to see how they interact with inequity and relative deprivation produced by our game.

Like many other psychology experiments, the experience of our study is not exactly like experiences in the everyday world. However, we hypothesize that the psychological mechanisms at work are the same. Unlike other studies on relative deprivation and collective violence, our paradigm measures actual, direct and face-to-face collective destructive efforts (rather than intention to join a protest, or individual aggressive behaviour), and unlike other studies of intergroup competition (e.g., [22]), our study allows groups to act in real time in a more realistic scenario. Such collective destruction would be despite incentives to maintain collective 


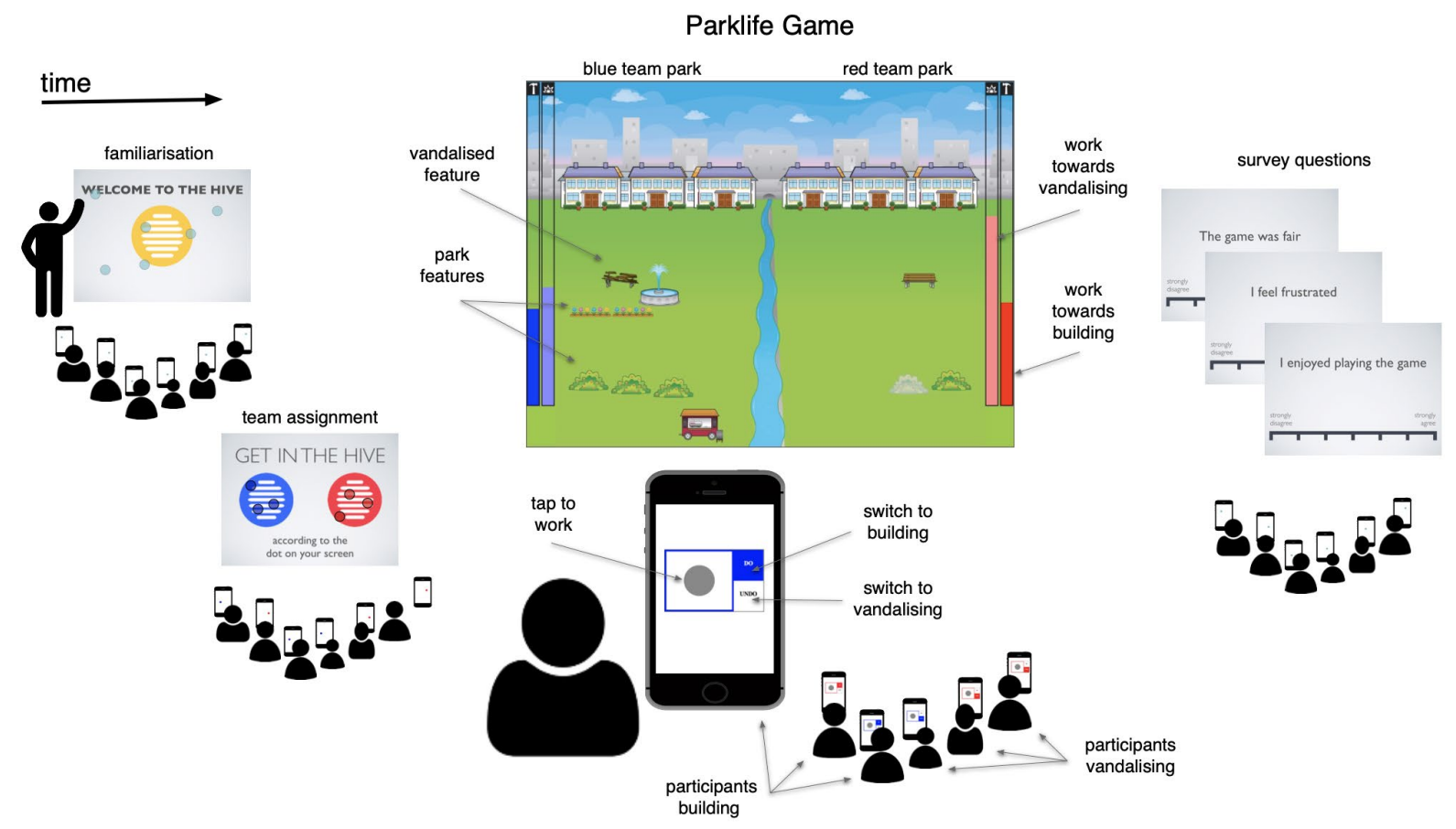

Figure 1. Schematic of a Parklife experiment. After being familiarised with the Hive interface ('familiarisation'), participants were placed into teams at random ('team assignment'). They played a Parklife game for 3 minutes (central screen), answered a series of questions ('survey questions'), and then played a second game with a new series of questions.

\section{RESULTS}

171 We ran 19 experimental sessions with a total of 203 participants. Internet connectivity issues 172 caused some data to be excluded, if, for example, the server could not assign the participant to a team, the participant was not active for the whole duration of the session, or if they had to reconnect to the server. This left us with 171 participants across 19 sessions with full data.

In the figures throughout, the disadvantaged team's actions are shown in red and the advantaged team in blue (though in the experiment, team colours were counterbalanced). For the equal games (when the teams are equitably rewarded for their work), the teams are shown in grey.

Figure 2 shows the actions that the teams took during the games, and the consequences they had for the parks, in terms of park features that were built and destroyed. As we predicted, in the so-called 'unequal' games (when one team has to work more than the other to produce a park feature), the disadvantaged teams built fewer park features and vandalised more of the other team's park features. 


\section{advantaged equal disadvantaged}
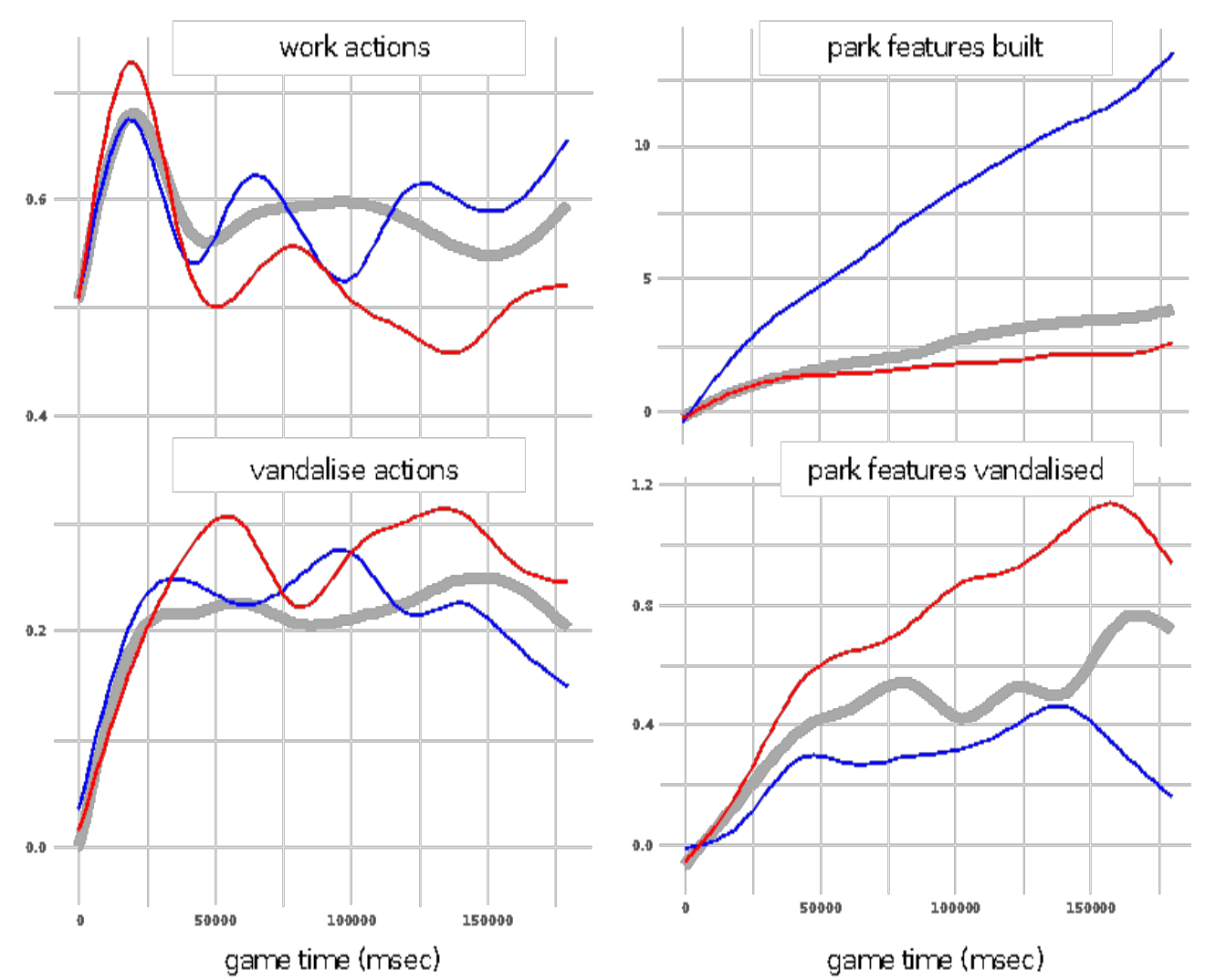

Figure 2. Averaged time-course of the probability of actions taken by participants (left) and the number of park features affected as a consequence (right) for advantaged and disadvantaged teams. At the top are work actions and features built, on the bottom are vandalise actions and features vandalised.

To test our hypothesis on the link between inequity, relative deprivation and collective destruction, we analysed individual's actions during the course of the games. Our key dependent variable was the vandalism rate: the number of participants' taps to undo (i.e., to vandalise the other team's park) as a proportion of the total number of taps that they made in the game. We analysed the vandalism rate as a function of game equality (equal vs. unequal), team membership (whether the individual was in the disadvantaged vs. advantaged team for the unequal game), and game order (whether they played the unequal game first or second). Figure 3 shows the observed vandalism rates for the advantaged and disadvantaged participants, in equal and unequal games. 


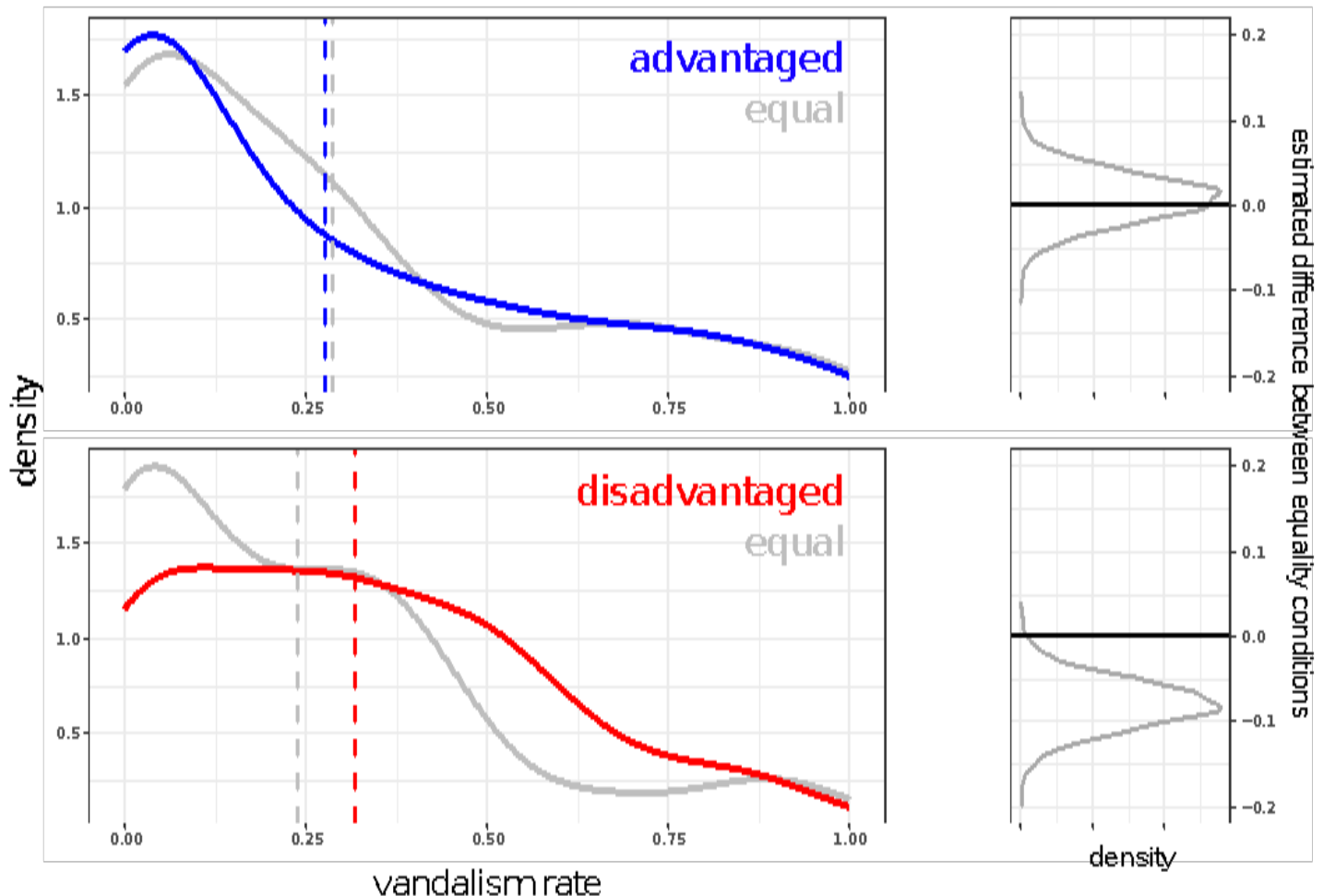

202 Figure 3. Distributions of the observed vandalism rates for the advantaged (top) and 203 disadvantaged (bottom) participants, when they were playing in the equal (grey) and unequal 204 (coloured) games. Mean rates in dotted lines. On the right are distributions of Bayesian 205 estimations of the differences between equal and unequal games, with $95 \%$ of distribution 206 shaded. The percentage of this distribution that is greater than zero is known as the Maximum 207 Probability of Effect (MPE), which directly quantifies the probability that the manipulation condition had an effect on behaviour. Here, it shows that there was only strong evidence of a difference between games for the disadvantaged teams.

211 We used Bayesian mixed models to quantify the evidence that each of our experimental factors 212 influenced participants' vandalism rate. Mixed models are able to account for the effect of 213 individual participants being nested in a particular group, and the Bayesian approach avoids some 214 of the problems associated with null hypothesis testing [23], or the need for a formal 'stopping 215 rule'. Our models employed weakly informative priors that were scaled following the standard 216 procedures (for full details and model specification see below).

218 In Figure 3, to the right of the observed data, we show the distributions of the estimated 219 differences between our experimental conditions. The percentage of this distribution that is 
220 greater than zero is known as the Maximum Probability of Effect (MPE), which directly quantifies 221 the probability that the manipulation condition had an effect on behaviour. We report below MPEs 222 for each of our experimental factors and contrasts within levels. The Bayesian approach favours 223 quantifying the strength of evidence in this way, rather than simply reporting whether or not an 224 (arbitrary) threshold of significance has been passed. Having said that, researchers generally 225 suggest that an MPE of above $90 \%$ or $95 \%$ can be thought of as 'strong evidence' [24]. In Figure 2263 , we can see a grey area that corresponds to $95 \%$ of the estimate distribution. When this 227 interval does not cover zero, it can be seen as strong evidence for a difference between 228 conditions. In addition to these Bayesian analyses, we ran frequentist analysis, which produced 229 a corresponding pattern of results (see Supplementary Material).

As predicted, there was an increase in vandalism rates for the disadvantaged teams when they were in the unequal game compared to the game where they were treated equitably (MPE=99.7\%). This was not the case for the advantaged teams, where there was no evidence of a difference between game types (MPE=62.1\%). There was evidence of a main effect of a higher amount of vandalism overall in the unequal games compared to the equal ones (MPE $=96.3 \%$ ), but no evidence of a higher amount of vandalism between the teams across all game types $(\mathrm{MPE}=52.2 \%)$. There was no evidence for more vandalism when unequal came first (MPE $=70.4 \%$ ), and no other factors had a significant impact on the proportion of vandalism across conditions.

241 As we were interested in how the experience of inequity changed participants' experience, they 242 privately reported how they felt about the game and each other after both the equal and unequal 243 game, on a number of custom-made items (see Figure 4, left). To quantify their response to 244 inequity, we subtracted their answers following the equal game from the answers following the 245 unequal game, and compared these difference scores between advantaged and disadvantaged 246 teams. We ran a Bayesian mixed model for each item, with the factors of team and game order, 247 nested in experimental group. From these runs, we generated distributions for the estimates of 248 the difference scores (Figure 4, centre) and calculated MPEs for each. 


$\begin{array}{lcl}\text { disadvantaged } & \begin{array}{c}\text { unequal game } \\ \text { advantaged }\end{array} & \text { estimate of team difference } \\ \text { between unequal-equal }\end{array}$

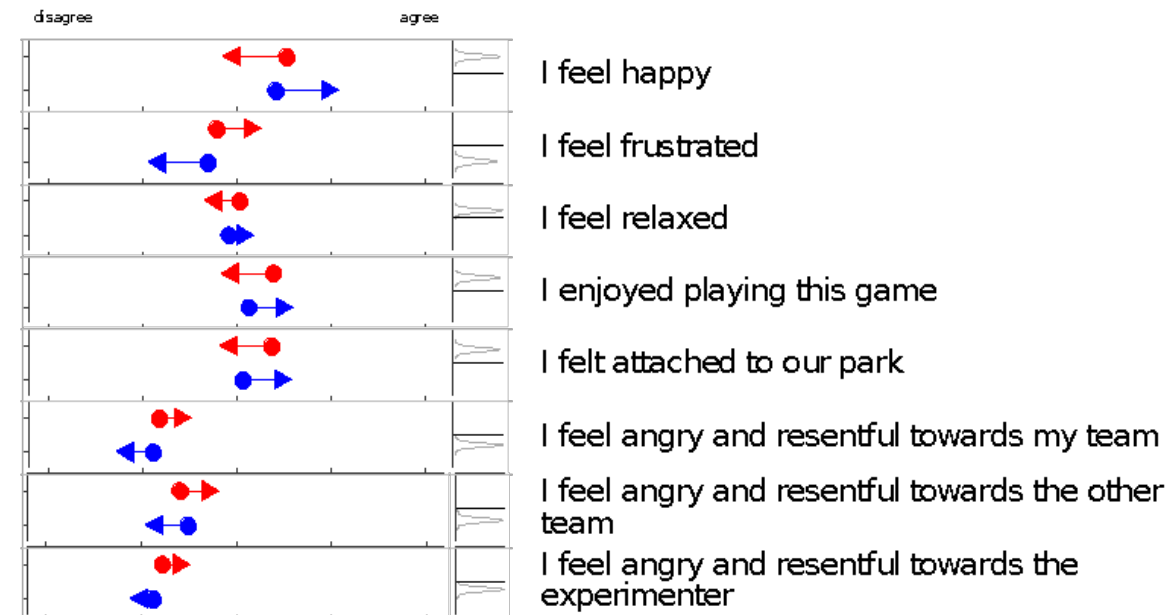

My team deserved more park features

My team was responsible for the outcome of the game

This game was fair

My team performed well in this game

I identified with my team

My team demonstrated its strength

I felt in control of my actions during this game

My teammates acted exactly like I did

I want to play this game again

Compared to the other team, my team was unfairly disadvantaged

Would you like to build a bridge between the two parks to connect them and share the park features built?

If your team eamed an extra monetary reward would you be willing to share?

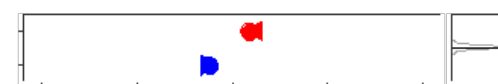

252 Figure 4. Responses to post-game survey items in the equal (circle) and unequal (triangle) 253 games. For example, the first item shows that (compared to the equal game) in the unequal game

254 the disadvantaged teams were less 'happy', whereas the advantaged teams were more 'happy'.

255 To the right are Bayesian estimates of differences between advantaged and disadvantaged teams

256 in the size and direction of these shifts in response inequity. In the first item, 95\% of this 257 distribution (shown in shaded area) does not include zero, and so there is strong evidence that 258 there is a reliable difference between teams. 
260 Inequity had a very different effect on participants' explicit ratings depending on whether they 261 were advantaged or disadvantaged. For all questions, MPEs were greater than 99.9\%, except 262 the two questions that asked if participants would act pro-socially towards the other team by 263 sharing a reward $(\mathrm{MPE}=80.8 \%$ ) or building a bridge between the parks (MPE $=90.3 \%)$. Critically, 264 the disadvantaged teams felt that they deserved more park features compared to what they have 265 got and that their team was unfairly disadvantaged, suggesting they experienced a shared fate 266 with others. They also reported higher frustration, anger and resentment in unequal vs. equal 267 games as compared to the advantaged teams. Interestingly, items linked to social identification 268 (whether people felt their team demonstrated its strength and identification with the team) were 269 higher in advantaged than disadvantaged teams.

\section{COMPUTATIONAL MODEL}

271 Our experimental work identified in the unequal game a set of causal factors that produced acts 272 of collective destruction. To understand how these factors may interact, we used computational 273 modelling. As individuals can interact with a number of others across different teams in continuous 274 time, we build an Agent Based Model (ABM) [25,26]. The model's goal was to evaluate two key 275 hypotheses: Individuals become frustrated through comparisons with better placed individuals or 276 groups; Also, and social identification and norms of behaviour play a role in escalating cycles of 277 conflict. Our ABM was designed to quantify - in the language of Parklife - whether individuals 278 vandalise at random, or whether it is due to social comparison and frustration, the creation of norms in each team, or some combination of factors.

280 To summarise the model's conclusions, both relative deprivation (in the form of park differences) 281 and other participant's behaviour is key to the increased proportion of vandalism in the 282 disadvantaged team in the unequal condition (more details may be found in the supplementary 283 material). We find there is a bias towards information from a participant's own team, and that 284 participants engage in coordinated behaviour, distributing vandalism and work across the 285 participants within their own team. Alongside this, we find positive evidence that those in the 286 disadvantaged condition are not behaving rationally, i.e., only vandalising through boredom or to 287 make something happen, and instead are responding to both park differences and the behaviour 288 of the other participants within the game. 
Our model is designed to mimic Parklife as closely as possible: each individual within the model is placed in a team in either the equal or unequal condition, plays the game for 180 seconds, and can work or vandalise. The model agents have access to the same information as the participants in Parklife, i.e., the number of features in the parks, and the number in each team working or vandalising at any one time. Agents may decide to work or vandalise based on park differences

294 or the behaviour of others. This information is taken from both teams, and which team agents 295 focus on when deciding whether to work or vandalise is biased (the details of which are described 296 shortly). Finally, the output of the model is the proportion of agents on each team vandalising in 297 each second.

We conclude that participants spend the majority of their time focusing on the state and behaviour of their own team. However, over time park differences increase, and so on the minority occasions that cross park comparisons are made, those in the unequal, disadvantaged condition become frustrated, and vandalise. In the full model, our findings suggest that players focus mainly on their own team, and coordinate their behaviour by performing the opposite function of those on their team (i.e. if many team mates are working, they vandalize, and vice versa). Participants balance team behaviour between working and vandalizing, providing evidence of coordinated behaviour across the teams.

To further test the motivations and mechanisms for vandalism in Parklife, we ran two simpler versions of the model: (the frustration-only and asocial models) in which individuals do not pay attention to others' behaviour. In the frustration-only model we remove the importance of social norms. The asocial model is designed to test if participants were simply tapping randomly or performing a cost-benefit analysis in keeping park differences to a minimum: if the latter those in the disadvantaged team in the unequal game would choose to vandalise rather than work with a

314 higher probability, as this decision reduces the effort to change the state of a park/reduce park 315 differences. Comparing our different models using Bayes factors, we find positive evidence for the full model over the asocial model (Bayes factor $=9.4$ ) and we therefore conclude that individuals are 319 behaving by neither tapping at a base rate, or tapping at an increased constant rate in only the 320 unequal, disadvantaged condition in order to keep park differences to a minimum. We found that 321 there is also strong evidence for the full model over one the frustration-only model (Bayes factor $322=12.8$ ), therefore showing the importance of social norms and team behaviour in Parklife. 
324 Our use of the term 'frustration' is not a commitment to any specific model of anti-social behaviour.

325 Emotional states are hard to identify, and therefore in this work we are using the catch-all term

326 'frustration' for the emotion driving vandalism within Parklife.

328 Table 1. Descriptor variables for the full model posteriors.

\begin{tabular}{|l|r|r|r|r|r|}
\hline Parameter & \multicolumn{1}{|l|}{ MAP } & \multicolumn{1}{l|}{ Median } & \multicolumn{1}{l|}{ Minimum } & \multicolumn{1}{l|}{ Maximum } & \multicolumn{1}{l|}{ MPE } \\
\hline Frustration level & 379 & 383 & 237 & 995 & 1 \\
\hline Imitation strength & -1.20 & -1.00 & -1.73 & -0.01 & 1 \\
\hline Base tapping rate & 0.62 & 0.56 & 0.32 & 0.78 & 1 \\
\hline Team bias & 0.74 & 0.72 & -0.94 & 0.97 & 0.99 \\
\hline
\end{tabular}
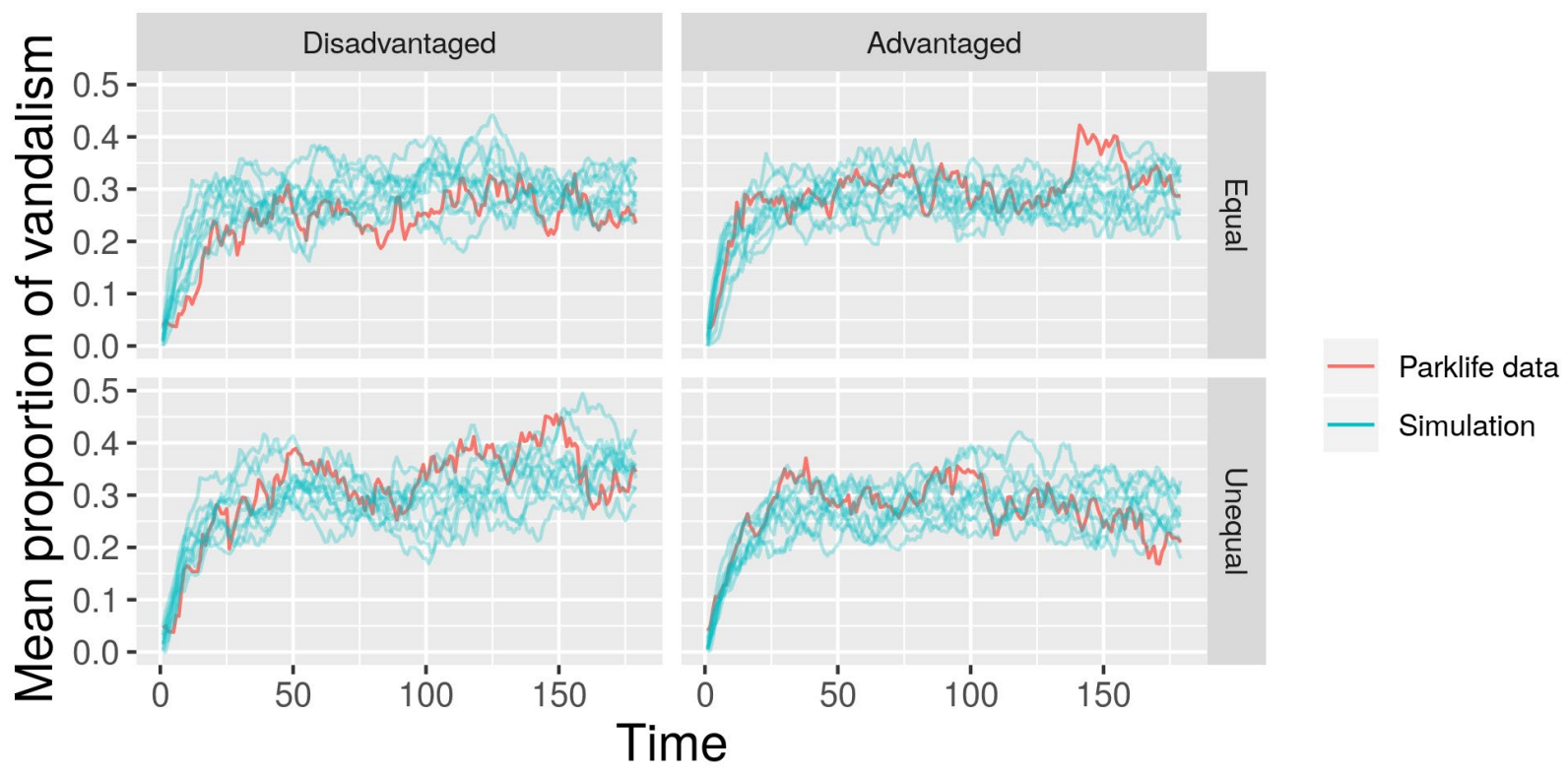

330 Figure 5. Ten example runs of the model using MAP point estimates of the posteriors for each 331 team and game condition (blue lines are a single simulation, red lines are the empirical data, both 332 averaged over 19 runs).

\section{DISCUSSION}

335 What are the psychological mechanisms that make people engage in violent collective behaviour? One view has been that when people feel they have less than deserved, they experience relative deprivation. This causes frustration and hostile aggression [4]. This explanation was questioned based on a lack of substantial empirical evidence $[10,28]$. Here, we used a lab based experimental approach to investigate behavioural and psychological responses to inequity, an approach which 
allowed us to directly measure actual collective destructive behaviour in response to perceived inequity. We found that the experience of being treated with inequity can lead to acts of collective aggression in a disadvantaged group, associated with reports of being unfairly treated together with one's own team. In our experiment, hostile behaviour took the form of damaging another team's park. This behaviour was also detrimental to the individuals themselves, as they were spending time vandalizing the opposition rather than improving their own park, or simply doing nothing. This suggests that these acts of collective destruction were not a cold, purely rational strategy to succeed at the task. Indeed, violent responses were associated with feelings of frustration, deprivation and of being treated unfairly.

Agent-based modelling confirmed this, and added further insight into how these psychological factors interact with additional factors associated with the emergence of riots in the literature, such as social identification and the importance of group norms [19]. Our best fitting model shows that, while frustration is a key explanatory variable for the increase in vandalism in disadvantaged groups, social identification and other's behaviour play an important role. In this model, participants begin focused on their own parks, with low initial frustration. However, on the relatively rare occasions when the disadvantaged group compares themselves to the advantaged group, their frustration and aggression levels spike. But individuals continue to act in relation to their team mates, ensuring that labour is distributed amongst vandalising and working. This interaction between individual frustration and team behaviour captures our experimental data better than frustration alone. The mechanisms demonstrated here may have wider ramifications for the study of collective behaviour, and in particular the effect that through coordinated action in a group setting, division of labour emerges naturally across each team.

One important distinction in the literature has been between individual (or personal) and collective (or fraternal) relative deprivation [13], with the finding that the latter may be necessary for collective action to occur. In Parklife, participants coordinate (as our models show) but it remains open whether they also explicitly understand that they are taking part in a collective action. The responses to the post-game questionnaire suggest they do as, e.g., members of the disadvantaged team felt their team was unfairly disadvantaged in unequal games, with a reduction of this belief in the advantaged team. This should be more directly addressed using additional post-game self-report items. 
373 Of course, tapping a given button in a virtual game is not equivalent to deciding to riot in the real 374 world. It was not the goal of Parklife or our models to accurately simulate a real riot. Although the 375 stakes and context are different, we contend that the same psychological mechanisms that turn 376 frustration into violence are at work. Experimental approaches such as these can help investigate 377 social behaviours that are difficult to study in the real world with precision or control. Our approach 378 offers a number of advantages over other non-social and non-realistic approaches. Participants 379 in Parklife meet with real participants and interact with them during the game; what's more, they 380 are meant to produce a virtual but perceivable object (a park), rather than allocating virtual resources they may have great difficulties representing. Our approach thus combines the benefits

It was not the goal of Parklife or our models to accurately simulate a real riot. Psychologists have learnt much about group processes, for example, using methods such as the minimal group paradigm. In typical experiments, participants are assigned to a group by an arbitrary or random criteria, and then asked to allocate abstract resources to in- and out-group members [39]. Real life social identities are not formed like this, of course, and in real life, we do not allocate resources to each other like that. Yet, the minimal group paradigm turns on the same psychological mechanisms that operate in the real world, and so provides insight into real world behaviour. Similarly, the goal of Parklife is not to recreate the circumstances of a riot, but to create a game that turns on the same mechanisms of social identification and relative deprivation.

Our results add to the evidence that essentialism - the notion that riotous crowds are simply made up of violent people - is an inadequate explanation. Since people were randomly assigned to experimental conditions, collective violence can be produced by the situation alone.

The game mimicked situations in which contributing to building an item is more costly than destroying it (the disadvantaged team had to work twice more to build, but vandalizing was equally costly between the teams). This asymmetry could contribute to the finding that members of the disadvantaged team prefer to vandalize in unequal games. Evidence from both the fact that 403 participants choose to vandalise rather than do nothing, and our modeling led us to argue that the 404 asymmetry between the two teams, introduced by contributing to building an item being more 405 costly than destroying it (the disadvantaged team had to work twice more to build, but vandalizing 406 was equally costly between the teams), results in relative deprivation, and it is this process which 
results in the increased vandalism. Of course, ruling out all processes through which this may occur is difficult, and any change in reward structure would result in an asymmetry of costs, introducing its own possibilities. This said, it is a necessary step to experimentally test this in the future, systematically and independently varying the relative costs and benefits of building and destroying in a fully factorial design, to test its impact on the observed individual and collective behaviour.

Social identification, social membership and histories are indisputable in the making of real world riots, and riots involve groups that are already socially structured, or at least, circumstances that favour shared identities and social norms [27,29]. Yet, minimal groups of randomly assigned teams have enough shared sense of identity to perceive their group as being treated unfairly and respond with aggression. In future work, we will explore how teams with different social membership and histories will respond differently to the experience of inequity.

Riots are a paradigmatic example of emerging collective behaviour, and as such, may be seen as a form of collective action. Although we have not explicitly differentiated between individual- or group-level relative deprivation ([13]) within Parklife, we observed the emergence of group level behaviour through the interactions of individuals. Although decisions are made on the individual level, information is received on the group-level, as only information on the parks and the total working or vandalising on each team is available. Within a dynamic group game such as Parklife,

427 it is therefore important to consider behaviour across all levels. Through this, our results may have 428 broader importance for group behaviour in other circumstances, both in humans and in other species. We find that coordinated behaviour emerges from an interaction of competition and cooperation, and that this is true even with relatively weak social identification (teams are only allocated at random, and no existing social identities are considered). When individuals are placed in a group environment with few restrictions, we still observe collective group behaviour. Finally, this work demonstrates the importance of inequity in the emergence of coordinated behaviour.

Unequal allocations have societal consequences [30]. In addition to the economic and practical difficulties caused by poverty, there might be a pervasive psychological response to real and 437 perceived inequity. These correlations have been observed historically at the population level, 438 and we understand little of the psychological responses to inequity at the behavioural level. Our 439 experiment and simulations provide evidence for one piece of this puzzle, showing that the 
440 experience of social inequity and the behaviour of others make people more likely to engage in

441 acts of collective aggression.

442

\section{METHODS}

444 Code

445 The code to reproduce the analyses can be found at:

446 https://osf.io/agbc3/

\section{Ethics}

449 We obtained ethical approval from the UCL Research Ethics Committee (Approval ID Number: $4503828 / 003)$.

\section{Subjects}

453 Since we were to employ Bayesian analysis (that does not require a pre-determined sample size or articulated stopping rule), we collected as much data as we could within a specific time window. Our sample size has therefore not been pre-registered. We tested 203 participants (129 females) in 19 groups. Participants were recruited from the SONA system of the University College London.

457 They were between 18 and 55 years old $(M=20.97, S D=4.57)$. They were compensated 5 GBP 458 for their participation, or given course credit. Our goal was to run participants in groups of 10. But 459 since it was challenging to recruit and ensure the attendance of exactly the same number of 460 participants each session, we ran opportunistically with whoever came to each session, resulting 461 in a range of group sizes from 4 to $23(M=9.63, S D=6.28)$. Pilot work suggested that within this 462 range group size did not have a systematic effect on vandalism rates. Internet connectivity issues 463 caused some data to be excluded. This left us with 171 participants across 19 sessions with full 464 data for analysis.

\section{Procedure}

467 Before taking part in the experiment, subjects were asked to fill in an online questionnaire. This 468 questionnaire measured a number of psychological traits. Upon arrival, subjects were seated in 469 a room, around a table, and were asked to fill in a participation consent form. On a voluntary 470 basis, participants could be equipped with a wristband to measure physiological indices (data to 471 be reported elsewhere). Participants were instructed to join the website 'thehive.sc' with their 472 smartphone or a tablet we provided. On this website, they provided a subject number we assigned 473 to them, as well as basic demographic information (gender and geographical area). Participants 
474 were then presented with a dot on their screen device that they could drag around with a finger.

475 We directed their attention to a central display which showed the dots of all participants moving 476 in real time.

478 Participants were then randomly assigned to two teams, which was indicated by the dots on their 479 device and on-screen changing colour. When the subjects were in odd numbers, one team 480 received one more player but participants were all told this would not affect the game outcome as 481 work effort is scaled by the system to accommodate different team numbers. They were then 482 instructed that they would play 2 games of Parklife, each lasting about 3 minutes, and would 483 answer some questions afterwards. They were asked not to speak during the game. The interface 484 (Figure 1) was explained to them, and they tried it out in a one-minute practice game while we 485 pointed out the information onscreen, and how the bars indicated their team's current actions 486 (Figure 1). By the end of the practice game we ensured that participants understood how to play.

Participants were asked not to speak during the game. They could see each other and potentially communicate non-verbally. Because teams were assigned randomly, they did not know which other participants were on their team. Explicit communication or planning within a team was difficult, and we did not observe any attempts.

Participants then played two Parklife games - one equal and one unequal (order counterbalanced between experimental sessions), together with whether the red or the blue team were advantaged or disadvantaged. In the unequal game, the amount of presses on the 'do' button necessary to generate a park feature was 2 times higher in one group than the other. This was not announced to the participants. The amount of presses on the 'undo' button to dismantle a feature in the park of the other team remained equal between groups. Between games, participants were randomly reassigned to red and blue teams, in an attempt to reduce carry over effects from one game to the next. Following each game was a set of custom-made survey questions (see Figure 4). Participants indicated their agreement with statements by moving a dot on their screen across a Likert scale (Figure 1). Finally, participants were asked debriefing questions, told the aims of our

\section{Statistical analysis}

506 Our mixed models used fixed effects for the participants team (advantaged / disadvantaged), the 507 game equality (equal / unequal) and game order (equal first / unequal first). There were random 
effects for the experimental group and the participant, with random intercepts. We used R (v. 3.4.3 [31]) and the package rstanarm (v. 2.18 [32]), employing weakly informative priors that were scaled following the standard rstanarm procedure (full priors are reported in the Supplementary Material). From 4000 samples, we generated estimates of the posterior distributions of the model parameter coefficients, which quantify the strength of the evidence that each experimental condition influenced behaviour in a consistent way. Below we report the estimates of the differences between experimental conditions, using the package psycho (v. 0.3.7 [33]).

We fitted a Markov Chain Monte Carlo, details of which can be found in Supplementary Material. Using the formula notation in the $\mathrm{R}$ stats package, the full model was specified as:

The model had an explanatory power of around $53.29 \%$ (Median Absolute Deviance $[M A D]=$ $0.043,95 \%$ Confidence Interval $=[0.44,0.61]$, adjusted $R^{2}=0.29$ ). Supplementary Material gives the full parameter estimates of the model with Median, Median Absolute Deviance (MAD), 95\% Confidence-Interval ( $\mathrm{Cl}-\mathrm{Cl}+$ ), Maximum Probability of Effect (MPE) and Overlap for each term. In addition to these Bayesian analyses, we ran frequentist analysis using more conventional mixed models. These produced a corresponding pattern of results and can be seen in the Supplementary Material.

\section{ACKNOWLEDGMENTS \& FUNDING}

531 This study has been funded by a grant from the Nuffield Foundation (The Psychological Roots of 532 Societal Self Harm, 42868) awarded to DCR, and a British Academy Newton International 533 Fellowship (NF 171514) and Alumni Follow-on Funding awarded to GD. GD also acknowledges 534 the support received from the Agence Nationale de la Recherche of the French government 535 through the program "Investissements d'Avenir" (16-IDEX-0001 CAP 20-25). 


\section{AUTHOR CONTRIBUTIONS}

539 G.D., J.V.Z and D.C.R. designed the study; G.D. and J.V.Z. collected the data; J.M.A. and D.C.R. 540 analysed the data; J.M.A developed the agent-based modelling; G.D., J.M.A. and D.C.R. wrote 541 the first version of the manuscript; All Authors revised the manuscript and approved the final 542 version.

\section{REFERENCES}

544 1. Braha D. 2012 Global civil unrest: contagion, self-organization, and prediction. PloS One 7, 545 e48596.

2. Bencsik P. 2018 The non-financial costs of violent public disturbances: Emotional responses to the 2011 riots in England. J. Hous. Econ. 40, 73-82.

3. Stott C, Drury J. 2017 Contemporary understanding of riots: Classical crowd psychology, ideology and the social identity approach. Public Underst. Sci. 26, 2-14.

550 4. Gurr TR. 2015 Why men rebel. Routledge.

551 5. Tilly C. 1971 Reviewed Work: Why Men Rebel by Ted Robert Gurr. J. Soc. Hist. 4, 416-420.

6. McPhail C. 1971 Civil disorder participation: A critical examination of recent research. Am. Sociol. Rev. , 1058-1073.

7. Miller AH, Bolce LH, Halligan M. 1977 The J-curve theory and the black urban riots: An empirical test of progressive relative deprivation theory. Am. Polit. Sci. Rev. 71, 964-982.

8. Spilerman S. 1976 Structural characteristics of cities and the severity of racial disorders. Am. Sociol. Rev. , 771-793.

9. Snyder D, Tilly C. 1972 Hardship and collective violence in France, 1830 to 1960. Am. Sociol. Rev. 37, 520-532.

10. Brush SG. 1996 Dynamics of theory change in the social sciences: Relative deprivation and collective violence. J. Confl. Resolut. 40, 523-545.

11. Muller EN. 1972 A test of a partial theory of potential for political violence. Am. Polit. Sci. Rev. 66, 928-959.

12. Walker L, Mann L. 1987 Unemployment, relative deprivation, and social protest. Pers. Soc. Psychol. Bull. 13, 275-283. and meta-analytic review. Personal. Soc. Psychol. Rev. 16, 203-232. 
570

571

572

573

574

575

576

577

578

579

580

581

582

583

584

585

586

587

588

589

590

591

592

593

594

595

596

597

598

599

600

601

602

603

604

15. Obaidi M, Bergh R, Akrami N, Anjum G. 2019 Group-Based Relative Deprivation Explains Endorsement of Extremism Among Western-Born Muslims. Psychol. Sci. 30, 596-605. (doi:10.1177/0956797619834879)

16. Greitemeyer T, Sagioglou C. 2016 Subjective socioeconomic status causes aggression: A test of the theory of social deprivation. J. Pers. Soc. Psychol. 111, 178.

17. Greitemeyer T, Sagioglou C. 2017 Increasing wealth inequality may increase interpersonal hostility: The relationship between personal relative deprivation and aggression. J. Soc. Psychol. 157, 766-776.

18. Abbink K, Masclet D, Mirza D. 2018 Inequality and inter-group conflicts: experimental evidence. Soc. Choice Welf. 50, 387-423.

19. Stott C, Ball R, Drury J, Neville F, Reicher S, Boardman A, Choudhury S. 2018 The evolving normative dimensions of 'riot': Towards an elaborated social identity explanation. Eur. J. Soc. Psychol. 48, 834-849.

20. Reicher SD. 1984 The St. Pauls' riot: An explanation of the limits of crowd action in terms of a social identity model. Eur. J. Soc. Psychol. 14, 1-21.

21. Smith ER, Conrey FR. 2007 Agent-based modeling: A new approach for theory building in social psychology. Personal. Soc. Psychol. Rev. 11, 87-104.

22. Aaldering H, Böhm R. 2019 Parochial Versus Universal Cooperation: Introducing a Novel Economic Game of Within- and Between-Group Interaction: Soc. Psychol. Personal. Sci. (doi:10.1177/1948550619841627)

23. Kruschke JK. 2010 What to believe: Bayesian methods for data analysis. Trends Cogn. Sci. 14, 293-300.

24. Sorensen T, Hohenstein S, Vasishth S. 2016 Bayesian linear mixed models using Stan: A tutorial for psychologists, linguists, and cognitive scientists. Quant. Methods Psychol. 12, 175-200. (doi:10.20982/tqmp.12.3.p175)

25. Davies TP, Fry HM, Wilson AG, Bishop SR. 2013 A mathematical model of the London riots and their policing. Sci. Rep. 3, 1303.

26. Epstein JM. 2002 Modeling civil violence: An agent-based computational approach. Proc. Natl. Acad. Sci. 99, 7243-7250.

27. Drury J et al. $2020 \mathrm{~A}$ social identity model of riot diffusion: From injustice to empowerment in the 2011 London riots. Eur. J. Soc. Psychol. n/a. (doi:10.1002/ejsp.2650)

28. McPhail C. 1994 The dark side of purpose: Individual and collective violence in riots. Sociol. Q. 35, 1-32.

29. Scacco A. 2009 Who Riots? Explaining Individual Participation in Ethnic Violence. Columbia University. 
605

606

607

608

609

610

611

612

613

30. Wilkinson RG, Pickett KE. 2009 Income inequality and social dysfunction. Annu. Rev. Sociol. 35, 493-511.

31. R Core Team. 2019 A language and environment for statistical computing. Vienna, Austria: R Foundation for Statistical Computing; 2012.

32. Goodrich B, Gabry J, Ali I, Brilleman S. 2016 rstanarm: Bayesian applied regression modeling via Stan. See https://mc-stan.org/rstanarm.

33. Makowski D. 2018 The psycho package: an efficient and publishing-oriented workflow for psychological science. J. Open Source Softw. 3, 470. 